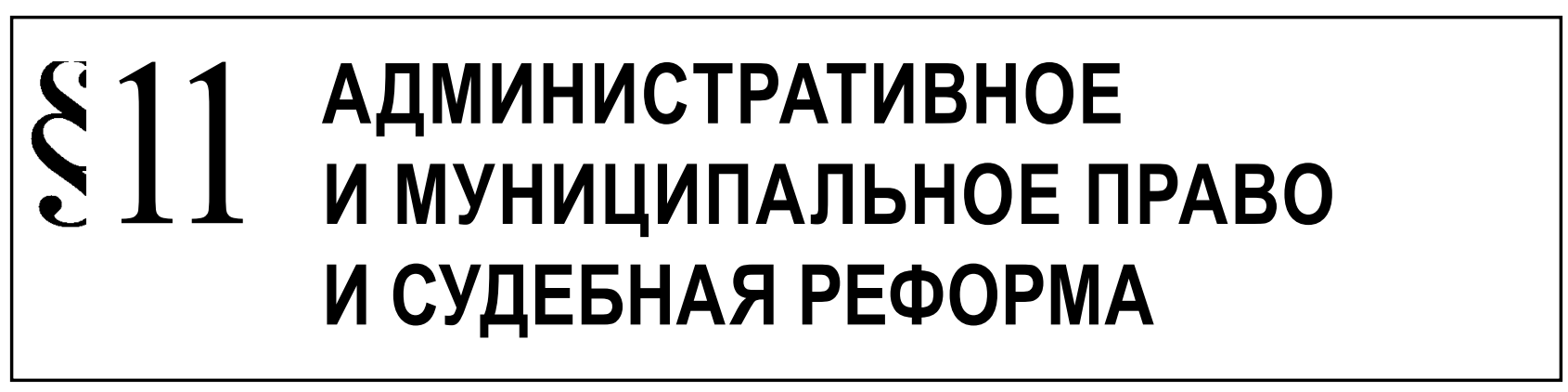

Шутилина О.А.

\title{
ТРИБУНАЛЫ КАК ФОРМА АДМИНИСТРАТИВНОЙ ЮСТИЦИИ
}

Аннотация. Одним из ключевых моментов этого исследования является тот факт, что трибуналы представляют собой альтернативный вид традиционному способу судебного контроля, как контроль за публичной администрацией. В научной статье исследуются правовая природа, а также законодательные нормы трибуналов. В дискуссии, которая последует вслед за этим, рассмотрим характеристики трибуналов и как они должны пониматься. В-третьих, некоторые признаки трибуналов были определены в общем и эти элементы также будут обсуждаться. Методологическую основу научной статьи составили общенаучные методы познания, в том числе: метод системного анализа, метод комплексного подхода, сравнительно-правовой, формально-логический, системно-структурный, формально-юридический, юридико-технический методы исследования. Надзор за трибуналами остается важной гарантией в отношении регулирования и ограниченности их функционирования. Будет показано обсуждение соответствующих особенностей, которые должен воплотить любой контролирующий орган. Наконец, будут продемонстрированы краткое изложение дебатов, касающиеся сферы действия юрисдикции трибунала, и некоторые их проблемы. Эти элементы должны обеспечить обзор по всеобъемлющей структуре трибунала.

Ключевые слова: административные трибуналы, обоснование решений, окончательность решений, законная сила решений, апелляция, пересмотр по существу, Судебный пересмотр, установлением фактов, процедура примирения, процессуальные нарушения.

Review: One of the key findings of this study is the fact that tribunals serve as an alternative to the traditional method of judicial review as public administration control. The article examines the legal nature and essential characteristics of tribunals. The author considers the characteristics of tribunals and the way they should be understood. Thirdly, certain features of tribunals have been identified generally, and these elements are also discussed. General scientific methods of cognition such as the methods of analysis, comparative methods, system and structural methods, legal and technical research methods form the methodological basis of the article. Tribunals supervision remains an important guarantee of regulation and circumscription of their functioning. The author discusses the relevant features which should be normal for any supervisory body. Lastly, the author demonstrates a short outline of the debates relating to the scope of tribunal jurisdiction, and some of their drawbacks. These elements should provide an over-arching supervision over a tribunal structure.

Keywords: merits review, appeal, legal force of decisions, ultimate decisions, justification of decisions, administrative tribunals, judicial review, fact-finding, conciliation, procedural impropriety.

0 дним из ключевых моментов этого исследования является тот факт, что трибуналы представляют собой альтернативный вид традиционному способу судебного контроля, как контроль за публичной администрацией. В результате необходимо исследовать основы, как трибуналы работают и состоят. Но не каждый компонент может быть рассмотрен, так как существует множество различных форм и видов трибуналов, поэ- тому была предпринята попытка осветить некоторые из наиболее общих и важных их особенностей.

Как объяснить и оправдать существование учреждений, выполняющих судебные функции, аналогичные судам, которые в то же время не являются частью судебной власти, а также укомплектованы должностными лицами, которым не гарантируют срок пребывания и зарплат, которыми обладают судьи? Статья поэтому обрисует в общих 
чертах важные элементы и особенности трибуналов в попытке иллюстрировать и оправдать их длительное существование в системах административного права.

Трибуналы - это неофициальные следственные или квазисудебные органы, которые имеют дело практически исключительно с административным правом, как правило, на очень специализированном уровне. Согласно Фармеру [1], трибуналы по определению должны обладать следующими характеристиками. Во-первых, они должны иметь полномочия принимать заключительные, юридически осуществимые решения. Во-вторых, они должны быть независимы от любой ведомственной власти. В-третьих, слушания, проводимые в трибуналах, должны иметь и общественный и судебный характер, но в то же время, они не обязаны безусловно выполнять строгие формальности суда, действующего по нормам общего права. В-четвертых, члены трибунала должны владеть определенными экспертными знаниями в рамках деятельности трибунала, а также судебными экспертными знаниями. В-пятых, трибуналы обязаны четко обосновывать принимаемые решения. И наконец, у сторон должно быть право обращаться в более высокий судебный орган при возникновении затруднений, касающихся вопросов права.

Согласно Говендеру [2], ценность данного определения заключается не в описании существующих трибуналов, а скорее в формулировке предпосылок, которые гарантировали бы оптимальную эффективность трибуналов в любой административной системе.

Как отправная точка перечисленные особенности являются предпосылками для эффективного функционирования трибуналов, в дальнейшем изучение и раскрытие последствий каждой из особенностей позволило бы создать общие критерии, по которым можно оценивать трибуналы.

В первую очередь следует уделить внимание понятиям окончательности (finality) и юридически законной силе решений (enforceability). Требование окончательности не подразумевает запрет обращения к более высокому суду, но обозначает, что решения, достигнутые трибуналами, являются не простыми рекомендациями, а скорее постановлениями, имеющими юридически законную силу. Требование окончательности отличает трибуналы от инстанций, не имеющих подобной власти, таких как комиссии по расследованию (commissions of inquiry) и комитеты по посредничеству (mediation committees). Трибуналы должны обладать доста- точной властью для исполнения принятого ими решения, иначе, возникает опасность того, что они становятся ни чем иным как органами, уполномоченными только выносить сторонам предложения рекомендательного характера.

Другая причина, почему трибуналы должны быть уполномочены принимать окончательные решения, заключается в сути разногласий, которые они призваны решать. Определенно в разрешении споров относительно гражданско-политических и социально-экономических прав ответственным органом обязано выступать правительство.

Принимая во внимание далеко идущие последствия, которые вызывают официальные действия в жизни человека, проверки, которые судебные или квазисудебные учреждения проводят в отношении исполнительной власти, должны вести к применению официальных мер, а не к вынесению простых заключений. Трибуналы должны быть уполномочены выносить решения с достаточной окончательностью, чтобы административные чиновники проверили, когда имело место злоупотребление властью или неумелое руководство административными действиями.

Во-вторых, трибуналы должны быть уполномочены принимать юридически осуществимые решения (legally enforceable decisions). Законная сила играет важную роль, поскольку юридическое осуществление принятого решения связано с функцией судебной власти. Контролируются ли трибуналы исполнительной властью, подпадают ли под контроль судебной власти, их решения должны вести к осуществимым последствиям. Любое решение, пока его результат не является полностью юридически осуществимым, не представляется эффективным, и чтобы сохранить общественное доверие к силе и власти трибуналов, их решения должны иметь законную силу.

Вторая характеристика трибуналов их независимость. Независимость судебной власти в Австралии закреплена в конституции и прецедентное право недвусмысленно подтвердило эту независимость. Если трибуналы должны рассматриваться как квазисудебный орган, как в английской модели, то их независимость, вероятно, гарантируется непроницаемой защитой. Кейн утверждает, что независимость является крайне важным фактором для эффективной деятельности судов в качестве внешней проверки принятия решений на правительственном уровне [3, с. 391].

Однако трибуналы обычно работают отлично от судов и не связаны такими правилами доказа- 
тельства, или строгим соблюдением требований судебной процедуры. Трибуналы должны быть нацелены на последовательное исправление, справедливость и соответствие естественным правовым нормам.

Трибуналы не обязательно следуют состязательной форме процедуры (adversarial procedure) и не обязаны придерживаться правил суда. По своей природе трибуналы нуждаются в постоянной связи с департаментами правительства, чьи решения они рассматривают, чтобы предложить более эффективные методы управления, и исправить ошибки, совершенные чиновниками. Они могут даже в большой степени зависеть от учреждений, чьи сотрудники рассматриваются, как потенциальные работники трибунала. Это вызывает проблемы, потому что, даже если членство комитета трибуналов остается независимым, чиновники и государственные служащие, работающие в системе трибуналов, могут произвести впечатление предвзятости. [4, с. 911-912]. Кейн выдвигает довод о том, что это просто вопрос политического выбора, что трибуналы не связаны с ведомствами, чьи действия они рассматривают, и что нет никакой существенной причины, почему внутренний пересмотр менее предпочтителен, чем пересмотр по существу административных решений (merits review) [3, c. 390]. Он признает, что общественное восприятие может играть важную роль в принятии решения о сохранении разделения трибуналов и правительственных департаментов. Шварц и Вейд также подтверждают роль независимости как определяющего фактора в деятельности трибуналов и заявляют, что трибуналы совершенно не подчиняются ведомствам, которые распределяют средства и осуществляют контроль [5, с. 145].

Как следствие, деятельность трибуналов можно выделить в отдельную категорию, учитывая, что даже в строгой системе разделения полномочий функции ведомств не определяются окончательно. В зависимости от того, в рамках какого ведомства функционируют трибуналы, судебное решение может приниматься исполнительной властью, действующей на законных основаниях, или в качестве альтернативы выступают судебные органы, осуществляющие исполнительное правосудие. В любом случае важно то, что при наличии взаимоотношений, основанных на сотрудничестве и содействии трибуналов и правительственных органов, существует степень независимости, при которой решения, принятые трибуналами, не подвергаются косвенному влиянию ведомств. Кейн демонстрирует различие между функциями судов и трибуналов через сопоставление судебного решения, рассматриваемого как инструмент управления, и судебного решения, выступающего в качестве механизма назначения ответственности [6]. В этом смысле суды ответственны за то, что берут на себя конституционную функцию правительственной системы, а именно, выносят резолюции и судебные решения по преступлениям и спорам, в то время как трибуналы призывают к ответственности чиновников, чтобы исправлять ошибки в их действиях.

Изначально вполне естественно, что слушания трибунала должны быть общественными и открытыми. Хотя публичное судебное разбирательство может казаться безошибочным способом, чтобы призвать к ответственности, добиться прозрачности слушаний и избежать необъективности трибунала $[4$, с. 786], в некоторых случаях это может быть абсолютно нежелательно. Одна из причин необходимости существования трибуналов заключается в том, что определенные иски могут касаться области, требующей высоких экспертных знаний, таких как налоговые споры или пособия по нетрудоспособности, где оценка нетрудоспособности предполагает медицинские экспертные знания. И часто такие дела имеют глубоко личный и деликатный характер. Например, признание нетрудоспособности может потребовать раскрытия всесторонней медицинской информации, налоговые споры влекут за собой обнародование информации о личном благосостоянии и объеме средств, в рамках жилищных исков может запрашиваться информация, касающаяся личной гигиены и условий жизни, которые могут быть очень конфиденциальными для претендента.

В то время как судебные слушания по таким же делам имеют публичную форму и открыты для общественности, суды могут обеспечить контроль и беспристрастность, поскольку судопроизводство в большой степени охраняется в соответствии с правилами представления свидетелей, свидетельств и доказательств и правилами приведения решений в действие. Чтобы соответствовать требованиям эффективности и продуктивности, трибуналы не обязательно подвергаются тем же самым ограничениям. Члены трибуналов могут начать работу на стадии ознакомления с делом, через подчиненных запросить в компетентных источниках материалы, раскрывающие специфические вопросы, провести опросы добровольных свидетелей и собрать письменные представления по проблеме. 
Они имеют полномочия не учитывать информацию, которая на их взгляд не имеет отношения к делу [7, с. 785]. Осуществление слушаний такого вида в открытой для общественности форме фактически может негативно отразиться на их эффективности и удобстве проведения, кроме того доступ общественности на заседание трибунала может быть закрыт, чтобы избежать нарушений, связанных с вторжением в частную жизнь. В Англии несколько трибуналов уже работают конфиденциально, например the Betting Levy Appeal Tribunal, Mental Health Review Tribunal, General and Special Commissioners of Income Тах. Другие слушания по требованию претендента могут быть проведены в частном порядке, где затрагиваются глубоко личные обстоятельства или есть угроза общественной безопасности. Такой частный подход не сохраняется при обращении в высшие судебные инстанции $[7$, с. 786]. “Общественная природа” слушаний скорее могла бы быть достигнута через предъявление к членам трибуналов требования опубликовать принимаемые ими решения в ясной, последовательной и всесторонне обоснованной форме. Это защитило бы достоинство и неприкосновенность личности истца, и кроме того установило бы систему, в рамках которой участники должны нести ответственность, а слушания имели бы прозрачный характер обсуждений. Статья 6 (1) Европейской конвенции по правам человека, которой должны придерживаться все европейские и британские трибуналы, не настаивает на публичных разбирательствах в случаях, если затронуты интересы общественного порядка или национальной безопасности, интересы несовершеннолетних, при защите частной жизни сторон или в интересах правосудия. Однако, в принципе, слушания должны всегда быть общественными и следует представлять обоснования для случаев, когда необходимо такое отклонение от нормы [7].

Согласно определению Фармера четвертая характеристика трибунала заключается в том, что члены трибунала должны обладать экспертными знаниями. Цель трибуналов состоит в том, чтобы обеспечить наиболее быстрое и максимально рентабельное разрешение административных споров, и таким образом требование, чтобы участники обладали глубокими и специфическими знаниями в рамках обсуждаемой проблемы очень важно для их эффективной работы. Это может выглядеть как довольно очевидное требование, но важнее не наличие знаний, а их уровень. К примеру, в Индии в отдельных юрисдикциях в состав трибуналов на- бирают не по экспертным характеристикам, а по социальному положению. Дэйтар заявляет, что трибуналы структурированы таким образом, что только государственные служащие, которые находятся на грани пенсии, заинтересованы принять в них участие [8]. Он приводит в пример Национальную организацию законных трибуналов Индии (NCLT). Любой член Гильдии адвокатов с пятнадцатилетним стажем имеет право стать членом трибунала, но срок полномочий ограничивается пятью годами без гарантии продления. Было бы абсурдно для опытных адвокатов оставить практику в разгаре карьеры, проработать в трибунале в течение пяти лет и затем возвратиться к практике с пятилетней потерей опыта. Индийский опыт состоит в том, что большинство государственных служащих принятых на работу в трибуналы уже пенсионеры или люди предпенсионного возраста. Это не желательно, поскольку трибуналы становятся для них своеобразными “воротами" для выхода на пенсию. А трибуналы должны привлекать высококвалифицированных участников, которым предлагались бы конкурентные преимущества и поощрения.

Поскольку в соответствующей области деятельности экспертиза обладает отдельной значимостью, особенно относительно исков, касающихся дохода, проблем жилищной политики, различных технических и специфических вопросов, судебные экспертные знания крайне необходимы. Трибуналы выполняют судебную функцию и принимают юридически осуществимые решения. В таком случае эти решения должны отвечать юридическим нормам и основываться на базовых ценностях, которым должны соответствовать все судебные решения. Непреложные ценности Конституции [9], такие как принцип законности и власти закона, равенство, человеческое достоинство и справедливость, а также ответственное и прозрачное управление должны поддерживаться в функционировании трибуналов. Судебные экспертные знания необходимы, чтобы гарантировать юридическую справедливость решений.

Пятая характеристика трибуналов по определению Фармера заключается в приведении обоснований, которое представляется далеко не новым понятием в административном праве. Приведение обоснований - это важная подтверждающая мера в любом административном судебном решении. Члены трибунала обязаны обосновать свои решения, в случае недостаточно убедительных обоснований назначается юридическая проверка. При таких условиях решения, принятые трибуналами, 
должны соответствовать более высоким стандартам. Предоставление «голых» заключений без обоснования причин будет всегда вызывать предположение, что трибунал не уделил делу достаточного внимания или что посторонние вопросы могли повлиять на объективность и основательность принятия решения. Требование обеспечения обоснований решений имеет несколько положительных сторон. Во-первых, обоснование способствует прозрачности процедуры и требует ответственности от членов трибуналов. Во-вторых, обоснования решения обеспечивают и административному чиновнику и претенденту удовлетворительное понимание того, почему было вынесено данное решение, что способствует формированию убежденности в справедливости правосудия. В-третьих, обоснования обеспечивают чиновников проектами мер по улучшению действующих принципов работы и рекомендациями по предотвращению подобных проблем. Надлежащее управление, таким образом, может осуществляться, начиная с основ административной работы, а не на более поздней стадии, где уже потребуется коррекция действий.
Последняя характеристика заключается в наличии права подавать в суд апелляцию по пунктам закона [5, с. 158]. Апелляция не является стандартной судебной проверкой. Хотя и то и другое допускает повторное рассмотрение административных решений. Судебный надзор касается ошибок в применении закона, в то время как апелляция позволяет добиться оптимально выгодного решения. В юрисдикции общего права, где трибуналы представляют собой часть административного механизма принятия судебного решения, суды продолжают играть важную контролирующую роль, как инстанция для подачи апелляции. Решения административных органов и трибуналов должны подчиняться условию возможности использовать право обжалования их в суде, что гарантирует, что правовая система остается по сути унитарной [5, с. 157].

Таким образом, были определены характеристики трибуналов, которые принимались в течение некоторого периода времени, но по сути, они проистекают из эффективного функционирования трибуналов.

\section{Библиография:}

1. Farmer Tribunals and Government. 1974. C. 184.

2. Govender Administrative Appeals Tribunals || in Comparing Administrative Justice. C. 77.

3. Кейн Административное право. С. 390.

4. Wade \& Forsyth Administrative Law. 2012.

5. Schwartz \& Wade Legal Control of Government. 1999.

6. Кейн Judicial Review in the Age of Tribunals in Forsyth, Elliott, Jhaveri, Ramsden \& Hill Effective Judicial Review: A Cornerstone of Good Governance. 2010. C. 493.

7. Justice All Souls Review. 2011. C. 221.

8. Дэйтар -The Tribunalisation of Justice in Indiall in Corder (ed) Comparing Administrative Justice Across the Commonwealth. 2007. C. 296.

9. S1 of the Constitution of the United States

\section{References (transliterated):}

1. Farmer Tribunals and Government. 1974. S. 184.

2. Govender Administrative Appeals Tribunals\| in Comparing Administrative Justice. S. 77.

3. Kein Administrativnoe pravo. S. 390

4. Wade \& Forsyth Administrative Law. 2012.

5. Schwartz \& Wade Legal Control of Government. 1999.

6. Kein Judicial Review in the Age of Tribunals in Forsyth, Elliott, Jhaveri, Ramsden \& Hill Effective Judicial Review: A Cornerstone of Good Governance. 2010. S. 493.

7. Justice All Souls Review. 2011. S. 221.

8. Deitar-The Tribunalisation of Justice in India\| in Corder (ed) Comparing Administrative Justice Across the Commonwealth. 2007. S. 296.

9. S1 of the Constitution of the United States 